\title{
Anti-proliferative and pro-apoptotic effects of 3,3'-diindolylmethane in human cervical cancer cells
}

\author{
JUNYONG ZHU, YUAN LI, CHAO GUAN and ZUHUA CHEN \\ Department of Gynecology, Renmin Hospital of Wuhan University, Wuchang, Wuhan 430060, P.R. China
}

Received April 12, 2012; Accepted May 25, 2012

DOI: $10.3892 /$ or.2012.1877

\begin{abstract}
The antitumor effects of Indo-3-carbinol (I3C) have been proven in many human carcinoma cells. However, the roles of 3,3-diindolylmethane (DIM), an important polymer converted from $\mathrm{I} 3 \mathrm{C}$ under $\mathrm{pH}$ 5.0-7.0, on the growth and proliferation of cervical cancer HeLa and SiHa cells still remain unrevealed. In the present study, we investigated the potential anti-proliferative and pro-apoptotic effects of DIM on HeLa and SiHa cells. Cell proliferation was detected by Cell Counting kit- 8 and apoptosis was analyzed by flow cytometry. In addition, morphological changes accompanying cell apoptosis were observed using an inverted microscope after Hoechst 33258 staining. In addition, expression changes of proteins involved in the MAPK and PI3K pathways were determined by western blotting. DIM treatment inhibited the proliferation and induced apoptosis of HeLa and SiHa cells significantly in a time- and dose-dependent manner. Moreover, SiHa cells were more sensitive to DIM treatment than HeLa cells $(\mathrm{P}<0.05)$. In addition, the expression of ERK, p38 and p-p38, which are involved in the MAPK pathway, was downregulated by DIM treatment. Another protein involved in the MAPK pathway, JNK, was upregulated. Furthermore, DIM treatment significantly suppressed the expression of Akt, p-Akt, PI3K p110 $\alpha$, PI3K p110 $\beta$, PI3K class III, GSK3- $\beta$, p-PDK1 and $\mathrm{p}$-c-Raf which are involved in the PI3K pathway. These results demonstrate that DIM exerts antitumor effects on HeLa and $\mathrm{SiHa}$ cells through its anti-proliferative and pro-apoptotic roles, especially for SiHa cells. The molecular mechanism for these effects may be related to its regulatory effects on MAPK and PI3K pathway and apoptosis proteins. DIM may be a preventive and therapeutic agent against cervical cancer.
\end{abstract}

\section{Introduction}

Cervical carcinoma is the second most common malignancy of female reproductive tract and ranks second among female deaths

Correspondence to: Dr Junyong Zhu, Department of Gynecology, Renmin Hospital of Wuhan University, 238 Jiefang Road, Wuchang, Wuhan 430060, P.R. China

E-mail: zhujunyong1974@163.com

Key words: 3,3'-diindolylmethane, cervical cancer, HeLa cells, $\mathrm{SiHa}$ cells, proliferation, apoptosis caused by cancers. More than 50 million people worldwide suffer from this disease each year. Although early diagnosis of cervical cancer has made great progress, the incidence and mortality of this disease still remains high, and the onset age is becoming younger, seriously threatening women's health and lives. The treatments mainly depend on surgery and radiotherapy, supplemented with chemotherapy. Five-year survival rate of terminally-ill patients is only $50 \%$ although therapeutic techniques have been improved greatly in the past years (1). It was reported that the poor effects of chemotherapy on advanced stage of cervical cancer may be directly due to obstacles in apoptosis of tumor cells (2).

Indole-3-carbinol (I3C), a type of compound derived from cruciferous vegetables (3), was demonstrated to exhibit significant anticancer efficacy both in vivo and in vitro by inducing cell apoptosis and cell cycle arrest in G1 phase (4,5), affecting DNA damage repair (6-8), as well as resisting angiogenesis, metastasizing and invasion of cancer cells $(9,10)$. 3,3'-diindolylmethane (DIM), an important polymer converted from I3C under pH 5.0-7.0 (11), was characterized with antiproliferative and pro-apoptotic activities in cancer cells $(12,13)$. Chinnakannu et al (13) reported that a formulated DIM (B-DIM) could inactivate $\mathrm{NF}_{-\mathrm{KB}}$ signaling and induce apoptosis through inhibiting proteasome activity in $\mathrm{S}$ phase of $\mathrm{LNCaP}$ and $\mathrm{C} 4-2 \mathrm{~B}$ cells, two types of prostate cancer cells, suggesting that B-DIM could be a potent agent for prevention and/or treatment of both hormone-sensitive and hormone-refractory prostate cancers. I3C-6, a derivative of I3C, was proven to significantly inhibit the growth and migration of HeLa cells (adenocarcinoma type) (14). However, there are no reports on anti-tumor effects of DIM in cervical carcinoma cells, or comparisons of its effects on two different types of cervical cancer cells, including HeLa cells (adenocarcinoma type) and $\mathrm{SiHa}$ cells (squamous carcinoma). The present study aimed to investigate the potential anticancer effects of DIM in cervical carcinoma cells in vitro and compare its different influence on HeLa cells and SiHa cells, thus providing useful information for clinical therapies of cervical carcinoma.

\section{Materials and methods}

Reagents. Cell Counting kit-8 (CCK-8) was purchased from Dongji (Japan). All antibodies were purchased from Cell Signaling Technology (USA), including p-p38, t-p38, p-ERK, t-ERK, p-JNK, t-JNK, PI3K p85, PI3K p110 $\alpha$, PI3K p110 $\beta$, 
p-Akt, t-Akt, p-PDK1, p-c-Raf and GAPDH. Annexin V FITC/ PI Apoptosis Detection kit was from Lianke (China).

Cell cultures. The HeLa cells and SiHa cells, kindly provided by the Type Culture Collection of Chinese Academy of Sciences, were maintained in RPMI-1640 medium (Sigma, USA) supplemented with $10 \%$ fetal bovine serum (FBS) (Hyclone, USA) and $20 \mu \mathrm{g} / \mathrm{ml}$ antibiotics (ampicillin and kanamycin). The cultivations were performed in a humidified atmosphere of $5 \% \mathrm{CO}_{2}$ at $37^{\circ} \mathrm{C}$. The medium was changed at 48 -h intervals and culture transfers were performed every 4 days when the culture almost reached confluence.

Measurement of cell proliferation. Cells were harvested by trypsinization at their logarithmic growth phases and plated in 96-well microwell plates in $100 \mu$ l RPMI-1640 medium with $10 \%$ FBS at a density of $1 \times 10^{3}$ cells/well. Cells were treated with DIM at different concentrations $(25,50$ and $100 \mu \mathrm{M})$ after $24 \mathrm{~h}$ of incubation and continuously cultured for 0,24, 48 and $72 \mathrm{~h}$ before proliferation analysis. Cell proliferation assays were performed using the WST- 8 based Colorimetric Assay Cell Counting kit-8 (CCK-8). In addition, proliferation was also measured in parallel negative groups without DIM treatment and the blank groups without cells in the wells. Six repeats were prepared for each group. Quantification of viable cells was performed by measuring the absorbance at $450 \mathrm{~nm}$ (A450) using a microplate reader (Beckman, USA). The following formula was used to calculate the inhibitory rate of DIM on cell proliferation: inhibitory rate $(\%)=[\mathrm{A} 450$ (negative group) $-\mathrm{A} 450$ (treated group)] / [A450 (negative group) - A450 (blank group)] x 100\%.

Apoptosis analysis. After DIM treatment for $48 \mathrm{~h}, \mathrm{HeLa}$ and SiHa cells were harvested by trypsinization $\left(\geq 1 \times 10^{4}\right)$ and washed twice with cold phosphate-buffered saline (PBS). The cells resuspended in $200 \mu \mathrm{l}$ annexin-V binding buffer were incubated in $5 \mu \mathrm{l}$ of annexin-V fluorescein isothiocyanate (FITC) solution and $10 \mu \mathrm{l}$ of propidium iodide (PI) solution for $15 \mathrm{~min}$ in the dark at room temperature. The fluorescences of each group were analyzed on a FACSCanto ${ }^{\mathrm{TM}}$ II spectrometer (BD Biosciences, San Jose, CA, USA) within $1 \mathrm{~h}$ and the cells stained with FITC/ PI were counted as apoptotic cells.

Western blot analysis. Proteins were extracted from the cultured cells and loaded onto a polyacrylamide gel $(10 \%)$. Then electrophoresis was performed at room temperature at $50 \mathrm{~V}$ for $30 \mathrm{~min}$ and then $200 \mathrm{~V}$ for $1.5 \mathrm{~h}$, followed by transferring to nitrocellulose membranes. The membranes were incubated with blocking solution for $2 \mathrm{~h}$ at room temperature, and then incubated with different primary antibodies including p-p38, t-p38, p-ERK, t-ERK, p-JNK, t-JNK, PI3K p85, PI3K p110 $\alpha$, PI3K p110 $\beta$, p-Akt, t-Akt, p-PDK1, p-c-Raf and GAPDH (Cell Signaling) for $12 \mathrm{~h}$ at $4^{\circ} \mathrm{C}$. After washing for $1 \mathrm{~h}$ with $20 \mathrm{mM}$ Tris $\cdot \mathrm{HCl}$ and $0.5 \mathrm{M} \mathrm{NaCl}$ (TBS) with $0.05 \%$ Tween-20 (TTBS), membranes were incubated with the secondary antibody conjugated to horseradish peroxidase for $30 \mathrm{~min}$ at room temperature and washed again for $1 \mathrm{~h}$. GAPDH was used as an internal reference. Protein bands were finally colored with enhanced chemiluminescence (ECL) reagent (Thermo, USA) and exposed to X-ray.
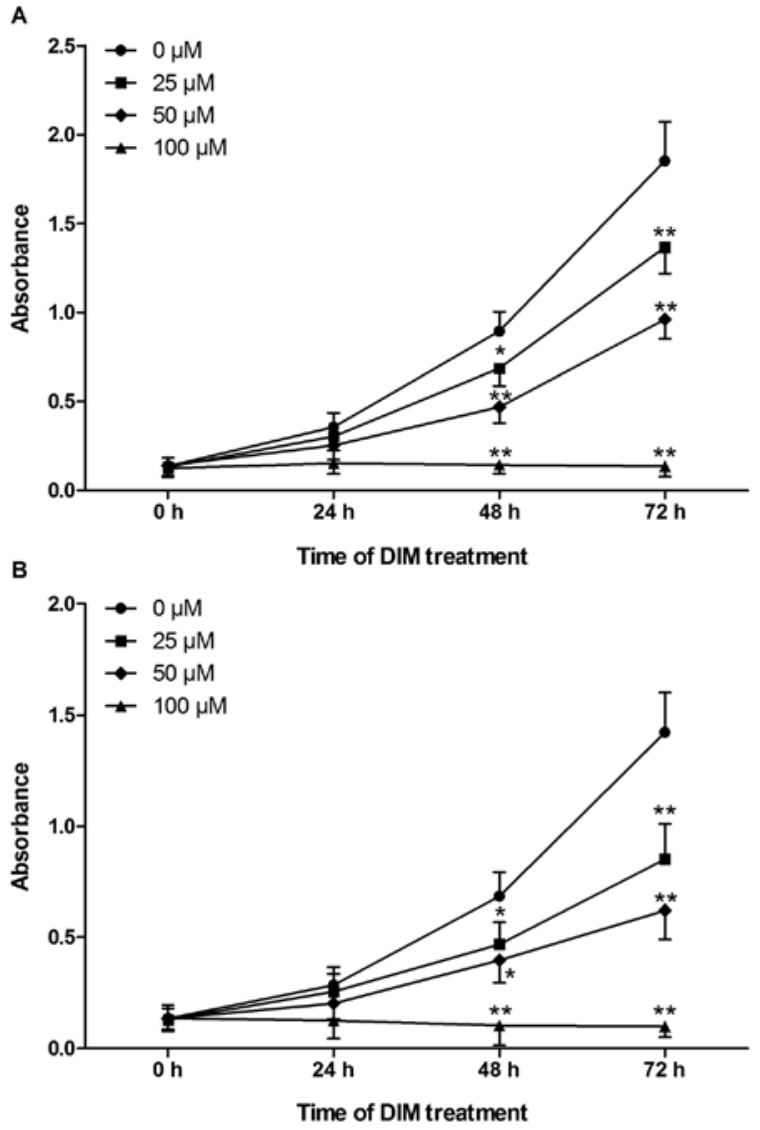

Figure 1. Effects of DIM treatment on the proliferation of HeLa cells (A) and SiHa cells (B). Cells were treated with various concentrations $(0-100 \mu \mathrm{M})$ of DIM for $0-72 \mathrm{~h}$. Cell proliferation was assessed by the CCK-8 method and represented by absorbance value at $450 \mathrm{~nm}$. Data are the mean \pm SD values obtained from five culture wells per group. ${ }^{*} \mathrm{P}<0.05$ and ${ }^{* *} \mathrm{P}<0.01$ compared with the control group.

Statistical analysis. Data are expressed as mean \pm SD. Difference in the effects of DIM on HeLa and SiHa cells were compared with one-way ANOVA (SPSS statistical software, SPSS Inc., Chicago, IL, USA). P $<0.05$ (two-tailed) was considered statistically significant.

\section{Results}

Effects of DIM on the proliferations of HeLa and SiHa cells. $\mathrm{HeLa}$ and $\mathrm{SiHa}$ cells were treated with various concentrations $(0,25,50$ and $100 \mu \mathrm{M})$ of DIM for $0-72 \mathrm{~h}$. Cell proliferation was assessed by the CCK-8 method and represented by absorbance value at $450 \mathrm{~nm}$. DIM showed a dose- and time-dependent antiproliferative effect on the growth of HeLa and SiHa cells (Fig. 1).

DIM showed a profound dose-dependent inhibition of the growth of $\mathrm{HeLa}$ and $\mathrm{SiHa}$ cells with the inhibitory rates ranging from 14.61 to 93.03 (Table I). It was noticeable that the inhibitory effects of DIM on SiHa cells were much stronger than that on HeLa cells after $48 \mathrm{~h}$ of treatment in each concentration group (except for $50 \mu \mathrm{M}$ group after $48 \mathrm{~h}$ of treatment). In addition, after DIM treatment for $48 \mathrm{~h}$, the calculated $\mathrm{IC}_{50}$ of DIM for $\mathrm{HeLa}$ and $\mathrm{SiHa}$ cells were 46.8 and $44.44 \mu \mathrm{M}$ respectively, suggesting a much more sensitive response of SiHa cells to DIM than that of HeLa cells. 
Table I. Inhibitory rates of DIM on the proliferation of HeLa and SiHa cells.

\begin{tabular}{|c|c|c|c|c|c|c|}
\hline \multirow[b]{2}{*}{$\operatorname{DIM}(\mu \mathrm{M})$} & \multicolumn{2}{|c|}{$24 \mathrm{~h}$} & \multicolumn{2}{|c|}{$48 \mathrm{~h}$} & \multicolumn{2}{|c|}{$72 \mathrm{~h}$} \\
\hline & HeLa & $\mathrm{SiHa}$ & HeLa & $\mathrm{SiHa}$ & HeLa & $\mathrm{SiHa}$ \\
\hline 25 & 14.61 & 10.18 & 23.38 & 31.58 & 26.19 & 40.04 \\
\hline 50 & 29.21 & 28.77 & 47.54 & 42.11 & 48.06 & 56.30 \\
\hline 100 & 57.02 & 56.14 & 84.00 & 84.94 & 92.66 & 93.03 \\
\hline
\end{tabular}

Cells were treated with different concentrations $(25-100 \mu \mathrm{M})$ of DIM for 0-72 $\mathrm{h}$. Cell proliferation was assessed by the CCK- 8 method and represented by absorbance value at $450 \mathrm{~nm}(\mathrm{~A} 450)$. Inhibitory rate (\%) $=[\mathrm{A} 450$ (negative group) $-\mathrm{A} 450$ (treated group) $] /[\mathrm{A} 450$ (negative group) - A450 (blank group)] x 100\%. DIM, 3,3'- diindolylmethane.

Effects of DIM on the apoptosis of HeLa and SiHa cells. Flow cytometry was performed to detect the apoptosis of HeLa cells and $\mathrm{SiHa}$ cells treated with various concentrations of DIM for $48 \mathrm{~h}$. As DIM concentrations increased from $0 \mu \mathrm{M}$ (negative control group) to $100 \mu \mathrm{M}$, both HeLa cells and SiHa cells showed the following tendencies (Fig. 2): i) The cells distributed in the 3rd region (normal zone) gradually decreased, indicating that the number of living cancer cells were reduced by DIM treatment. ii) The cells distributed in the 4th region gradually increased, suggesting the number of cells at early stage of apoptosis were increased after DIM treatment. iii) The number of cells with broken nuclei, which would be distributed in the 2nd region (advanced apoptosis cells), also increased with the increment of DIM concentrations.
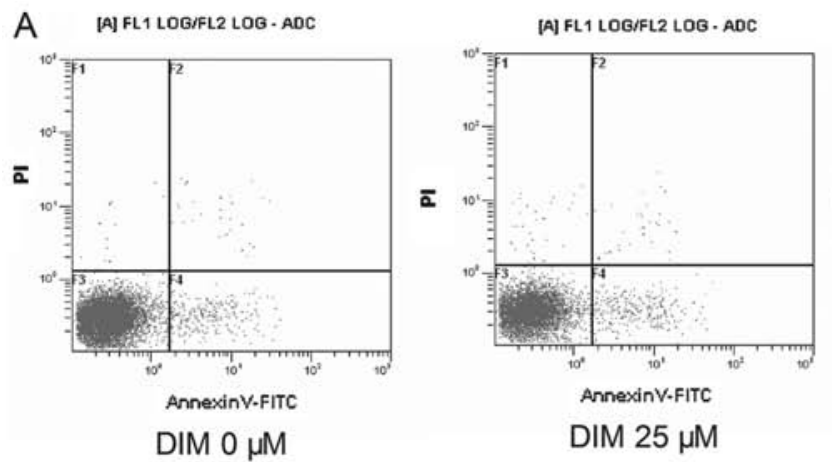

B
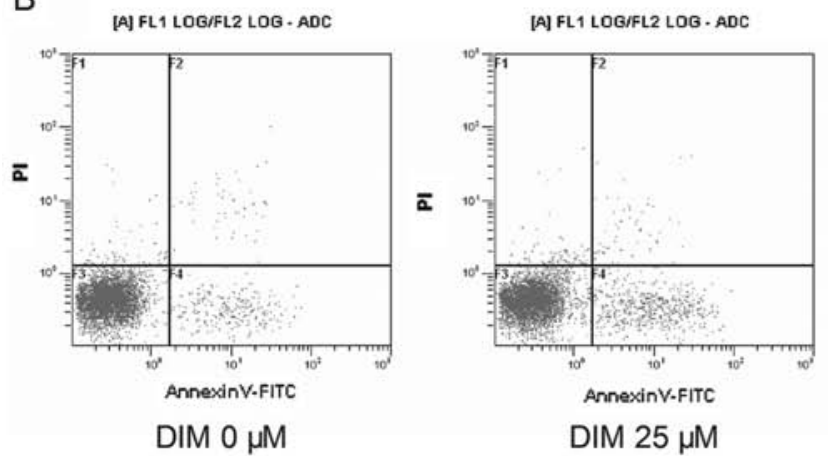

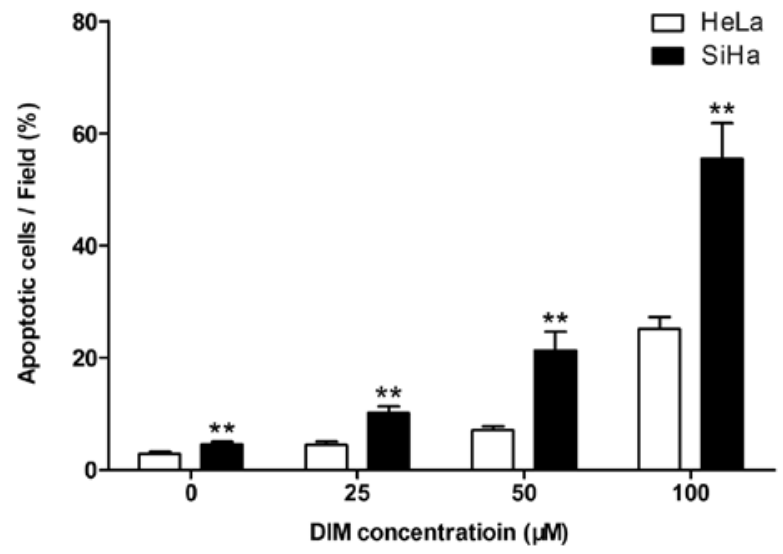

Figure 3. Comparisons of pro-apoptotic effects of DIM treatment on HeLa cells and $\mathrm{SiHa}$ cells. Cells were treated with various concentrations $(0-100 \mu \mathrm{M})$ of DIM for $48 \mathrm{~h}$. Flow cytometry was performed for apoptosis analysis and apoptotic ratio was expressed as the percentage of apoptotic cells over total cells in each field. ${ }^{* *} \mathrm{P}<0.01$ compared with HeLa cells.

DIM showed a significantly stronger pro-apoptotic effect on SiHa cells compared with HeLa cells (Fig. 3). Apoptosis was induced in $(4.45 \pm 0.56),(7.11 \pm 0.67)$ and $(25.16 \pm 2.12) \%$ of HeLa cells at 25, 50 and $100 \mu \mathrm{M}$ DIM respectively, while the apoptotic ratio in SiHa cells were (10.09 \pm 1.32$),(21.11 \pm 3.36)$ and (55.46 \pm 6.33$) \%$ at each concentration (all $\mathrm{P}<0.01$ ).

Effects of DIM on the expressions of proteins involved in apoptosis. Among many apoptosis pathways, the activation of mitogen-activated protein kinases (MAPK) and phosphoinositide 3-kinases (PI3K) signaling pathways drive a significant

Figure 2. Detection of apoptosis in HeLa cells (A) and SiHa cells (B) after DIM treatment. Flow cytometry was performed for apoptosis analysis of HeLa cells and $\mathrm{SiHa}$ cells treated with various concentrations $(0-100 \mu \mathrm{M})$ of DIM for $48 \mathrm{~h}$. 
A

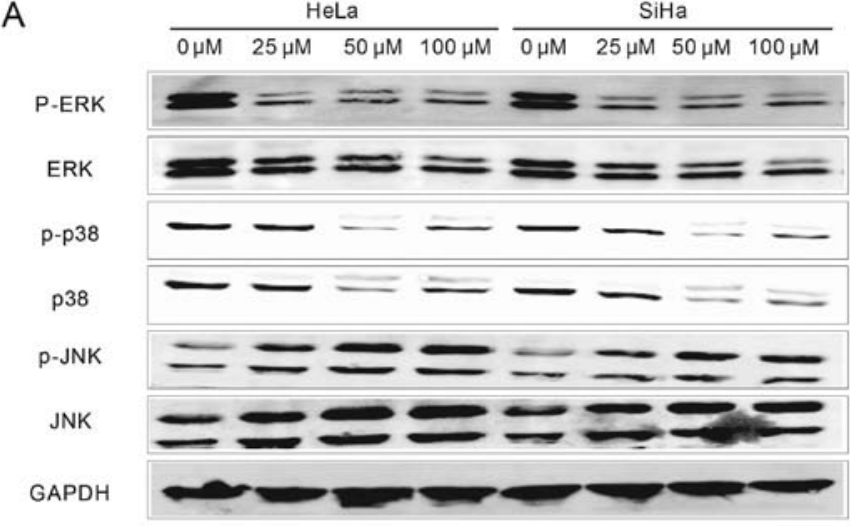

B

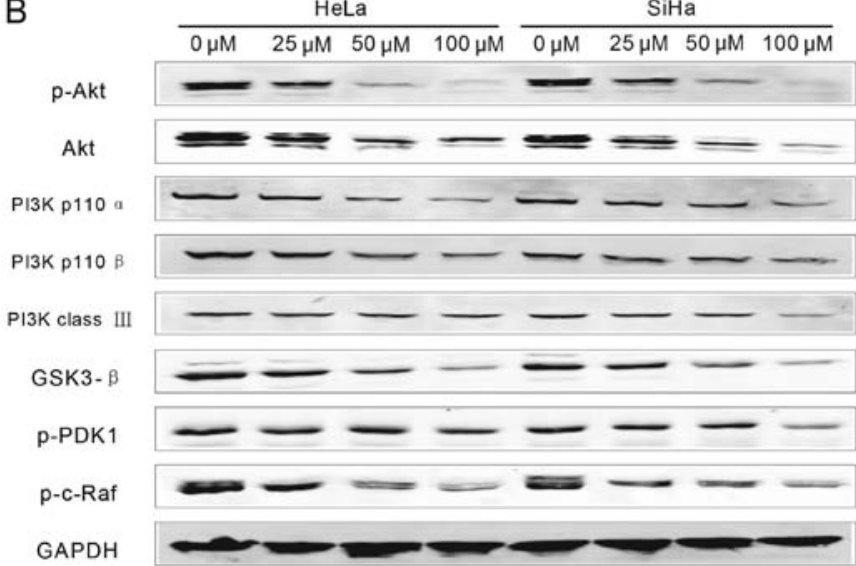

Figure 4. Expression changes of proteins involved in MAPK and PI3K pathways after DIM treatment. Cells were treated with various concentrations $(0-100 \mu \mathrm{M})$ of DIM for $48 \mathrm{~h}$.

percentage of human cancer and serve as the targets for drug development. Western blottting was performed to determine the expression changes of proteins involved in these two pathways. The results showed that expression levels of different proteins involved were more or less influenced by DIM treatment. As shown in Fig. 4, GAPDH, the internal reference, remained stable in the two types of cells before and after DIM treatment. For MAPK pathway (Fig. 4A), the expression levels of extracellular signal regulated kinase (ERK), as well as the levels of phosphorylated ERK (p-ERK), were all decreased in HeLa and SiHa cells in accordance with the increase of DIM concentration. p38 and p-p38, also proteins involved in MAPK pathway, were downregulated with relatively lower DIM concentrations (25 and $50 \mu \mathrm{M}$ ), but then upregulated when the concentration reached $100 \mu \mathrm{M}$. Moreover, the expression levels of p38 and p-p38 in SiHa cells treated with $100 \mu \mathrm{M}$ DIM were lower than those in HeLa cells. Another protein involved in MAPK pathway, c-Jun $\mathrm{N}$-terminal kinase (JNK), was upregulated by DIM treatment in a dose-dependent manner, accompanied with the increase of phosphorylated JNK (p-JNK) and there were no evident differences between HeLa and $\mathrm{SiHa}$ cells.

For proteins involved in PI3K pathway (p110 $\alpha$, p110 $\beta$, class III, Akt, GSK3- $\beta$, p-PDK1 and p-c-Raf) (Fig. 4B), their expressions and phosphorylation levels were all downregulated in both HeLa and SiHa cells by DIM treatment with decreasing the drug concentration. In addition, the expression levels of
Akt, PI3K class III, GSK3- $\beta$, and p-PDK1 of SiHa cells treated with $100 \mu \mathrm{M}$ DIM were significantly lower than those of HeLa cells.

\section{Disscussion}

There is well documented evidence that I3C, a natural anticancer compound extracted from cruciferous vegetables, exerted antiproliferative effects on many cancers in vitro, including breast, colon and prostate cancers $(12,13)$. While DIM, the polymer converted from I3C under acidic conditions, was suggested to be the real actor during anticancer process induced by I3C (15). In the present study we investigated the effects of DIM on the proliferation and apoptosis of HeLa and SiHa cells, as they are two different typical types of cervical cancer cells.

In the present study it was demonstrated that DIM inhibited proliferation and induced apoptosis in $\mathrm{HeLa}$ and $\mathrm{SiHa}$ cells in a time- and dose-dependent manner, consistent with other reports concerning the anti-proliferative and pro-apoptotic ablities of DIM $(12,13)$. Interestingly, SiHa cells, a type of squamous carcinoma cells, seemed to be more sensitive to DIM treatment than the adenocarcinoma cells (HeLa cells), contrary to the effects of many other anti-cancer compounds. According to Zhou et al (16), artesunate inhibited the growth of HeLa cells more efficiently than $\mathrm{SiHa}$ cells, and it also increased the radio-sensitivity of HeLa cells but not $\mathrm{SiHa}$ cells. Cisplatin, a widely-used drug in cancer chemotherapy, was demonstrated to be more effective in HeLa cells compared with $\mathrm{SiHa}$ cells (17). However, Han et al (18) found that extracts from shiitake (Lentinula edodes) mycelial culture broth, by an organic solvent ethyl acetate, inhibited the proliferation of cultured tumor cells, including Caski, SiHa, HeLa, HP-1 and A375 cells. Among them, HeLa cells showed lower sensitivity to the extracts than $\mathrm{SiHa}$ cells, not only in cell growth, but also in fragmentation of DNA, as well as the activity of caspase-3 in cancer cell extracts. In the present study a similar phenomenon for DIM treatment was observed.

Mitogen-activated protein kinases (MAPK), including ERK, JNK, and p38 MAPK (19), are ubiquitous serine/threonine protein kinases that have been implicated in many cellular processes such as proliferation, differentiation, and apoptosis $(20,21)$. Human MAPK pathway was often deregulated in cancer cells (22) and thus considered as potential therapeutic targets (23). Elevated ERK activity was frequently observed in human tumors and suggested to be a good indicator of tumor progression and evaluation of the efficacy of therapeutic agents (24-26). Studies have shown that targeting ERK1/2 using siRNAs effectively reduced lung metastasis and sensitized tumor cells to chemotherapeutic agents such as cisplatin $(25,27)$. The activation of $\mathrm{p} 38$ was also reported to be elevated in human non-small cell lung cancer (28) and the inhibition and reduction of $\mathrm{p} 38$ by inhibitor or RNAi could restrain the invasion and movement of cancer cells (29-31), suggesting the important roles of p38 in oncogenesis, tumor development, tumor invasion and metastasis. Several reports also provided evidence on JNK's function as proapoptotic kinase in response to various stimuli (32-37). The inhibitory effect of DIM on the proliferation of cervical cancer cells, as well as the induction of apoptosis in the present study, were demonstrated to be accompanied by downregulation of ERK, P38, and upregula- 
tion of JNK, indicating that MAPK pathway was involved in the pro-apoptotic effects of DIM treatment on HeLa and $\mathrm{SiHa}$ cells, which was consistent to reports on other cancer cells. However, it remained unclear why expression of p38 and p-p38 was reduced at relatively lower concentration of DIM treatment, but then increased at the concentration of $100 \mu \mathrm{M}$. This might be explained by a compensatory mechanism triggered at the advanced apotosis stage since the main function of $\mathrm{p} 38$ was to protect cells from apoptosis (38).

PI3K, a major signaling hub downstream of HER2 (human epidermal growth factor receptor 2) and other receptor tyrosine kinases (RTKs), activates Akt, SGK, PDK1, mTOR, and several other molecules involved in cell cycle progression and survival (39). Three classes of PI3K enzymes have been defined and class $\mathrm{I}$ is the most intensely studied which includes $\mathrm{p} 110 \alpha, \beta$, $\gamma$, and $\delta$ catalytic isoforms (40). As a direct downstream target of PI3K, Akt is also a key oncogenic survival factor and can phosphorylate and inactivate a panel of critical proapoptotic molecules, including Bad, caspase 9, GSK3- $\beta$, cell cycle inhibitors p21 and p27, and tumor suppressor TSC2 (41-45). The PI3K pathway is an important regulator in cell survival, proliferation, and apoptosis. Moreover, it is one of the most frequently altered networks in cancer (46). Overexpression of PI3K/AKT was observed recently in various malignant tumors, such as cervical carcinoma (47), prostate cancer (48), as well as breast cancer (49). Furthermore, PI3K p110 expression was detected to be positive in all stages of cervical lesions except normal cervical tissue (50). The inhibitors of PI3K or Akt, curcumin (51), celecoxib (52), perifosine (53-55) and CMEP (56), were all reported to attenuate the growth and proliferation of cancer cells and induce cell apoptosis. In the present study, downregulation of proteins associated with PI3K/Akt signaling pathway in HeLa and SiHa cells suggested that this pathway was also involved in the apoptosis of cervical cancer cells due to DIM treatment. In addition, different expression changes of p38, p-p38, Akt, PI3K classIII, GSK3- $\beta$, and p-PDK1 after DIM treatment between SiHa cells and HeLa cells might explain their different sensitivities to DIM treatment.

In conclusion, according to our results in the present study, DIM showed evident anti-proliferative and pro-apoptotic effects on cervical carcinoma cells in time and dose-dependent manner, and SiHa cells presented a stronger sensitivity than HeLa cells. MAPK and PI3K signaling pathways were proven to be involved in the pro-apoptotic effects of DIM on cervical cancer cells. Given that DIM exerted the above anti-tumor effects, especially on SiHa cells, it might be helpful for the development of novel therapeutic compounds for cervical cancers. Specific therapies for different types of cervical carcinoma are necessary since they react differently to different drugs.

\section{References}

1. Newall AT, Beutels P, Wood JG, Edmunds WJ and MacIntyre CR: Cost-effectiveness analyses of human papillomavirus vaccination. Lancet Infect Dis 7: 289-296, 2007.

2. Tanaka T, Bai T, Yukawa K and Umesaki N: Optimal combination chemotherapy and chemoradiotherapy with etoposide for advanced cervical squamous cancer cells in vitro. Oncol Rep 15: 939-947, 2006.

3. Sarkar FH, Li Y, Wang Z and Kong D: Cellular signaling perturbation by natural products. Cell Signal 21: 1541-1547, 2009.

4. Brew CT, Aronchik I, Hsu JC, et al: Indole-3-carbinol activates the ATM signaling pathway independent of DNA damage to stabilize p53 and induce G1 arrest of human mammary epithelial cells. Int J Cancer 118: 857-868, 2006.
5. Chinni SR, Li Y, Upadhyay S, Koppolu PK and Sarkar FH: Indole-3-carbinol (I3C) induced cell growth inhibition, G1 cell cycle arrest and apoptosis in prostate cancer cells. Oncogene 20: 2927-2936, 2001

6. Rahman KM, Aranha O, Glazyrin A, Chinni SR and Sarkar FH: Translocation of Bax to mitochondria induces apoptotic cell death in indole-3-carbinol (I3C) treated breast cancer cells. Oncogene 19: 5764-5771, 2000.

7. Cover CM, Hsieh SJ, Tran SH, et al: Indole-3-carbinol inhibits the expression of cyclin-dependent kinase- 6 and induces a G1 cell cycle arrest of human breast cancer cells independent of estrogen receptor signaling. J Biol Chem 273: 3838-3847, 1998.

8. Fan S, Wang J, Yuan R, et al: BRCA1 inhibition of estrogen receptor signaling in transfected cells. Science 284: 1354-1356, 1999.

9. Meng Q, Qi M, Chen DZ, et al: Suppression of breast cancer invasion and migration by indole-3-carbinol: associated with up-regulation of BRCA1 and E-cadherin/catenin complexes. J Mol Med 78: 155-165, 2000.

10. Chang X, Tou JC, Hong C, et al: 3,3'-Diindolylmethane inhibits angiogenesis and the growth of transplantable human breast carcinoma in athymic mice. Carcinogenesis 26: 771-778, 2005.

11. Safe S, Papineni S and Chintharlapalli S: Cancer chemotherapy with indole-3-carbinol, bis(3'-indolyl)methane and synthetic analogs. Cancer Lett 269: 326-338, 2008.

12. Khwaja FS, Wynne S, Posey I and Djakiew D: 3,3'-diindolylmethane induction of p75NTR-dependent cell death via the p38 mitogen-activated protein kinase pathway in prostate cancer cells. Cancer Prev Res 2: 566-571, 2009.

13. Chinnakannu K, Chen D, Li Y, et al: Cell cycle-dependent effects of 3,3'-diindolylmethane on proliferation and apoptosis of prostate cancer cells. J Cell Physiol 219: 94-99, 2009.

14. Ge C, Xu J and Jiao Y: New derivatives I3C-6 of indole-3-carbinol in cervical cancer HeLa cells. Suzhou University J Med Sci 29: 838-834, 2009.

15. Chang YC, Riby J, Chang GH, Peng BC, Firestone G and Bjeldanes LF: Cytostatic and antiestrogenic effects of 2-(indol3-ylmethyl)-3,3'-diindolylmethane, a major in vivo product of dietary indole-3-carbinol. Biochem Pharmacol 58: 825-834, 1999.

16. Zhou Y, Feng Y and Zhang X: Study on the effect of artesunate combined with irradiation on DNA damage of HeLa and SiHa cells of human cervical cancer. J Radiat Res Radiat Process 29: 33-36, 2011.

17. Wang H, Zhang Y and Jiang K: Enhancement of photodynamic therapy sensitivity by cisplatin in human cervical carcinoma cell lines. J Xian Jiaotong University (Med Sci ) 31: 625-630, 2010.

18. Han B, Toyomasu T and Shinozawa T: Induction of apoptosis in cultured cells by extracts from shiitake (Lentinula edodes) mycelial culture broth. Mycoscience 41: 623-631, 2000.

19. Fecher LA, Amaravadi RK and Flaherty KT: The MAPK pathway in melanoma. Curr Opin Oncol 20: 183-189, 2008.

20. Seger R and Krebs EG: The MAPK signaling cascade. FASEB J 9: 726-735, 1995.

21. Cobb MH: MAP kinase pathways. Prog Biophys Mol Biol 71: 479-500, 1999.

22. Meira DD, de Almeida VH, Mororo JS, et al: Combination of cetuximab with chemoradiation, trastuzumab or MAPK inhibitors: mechanisms of sensitisation of cervical cancer cells. Br J Cancer 101: 782-791, 2009.

23. Inamdar GS, Madhunapantula SV and Robertson GP: Targeting the MAPK pathway in melanoma: why some approaches succeed and other fail. Biochem Pharmacol 80: 624-637, 2010.

24. Lopez-Bergami P, Huang C, Goydos JS, et al: Rewired ERK-JNK signaling pathways in melanoma. Cancer Cell 11: 447-460, 2007.

25. Mirmohammadsadegh A, Mota R, Gustrau A, et al: ERK1/2 is highly phosphorylated in melanoma metastases and protects melanoma cells from cisplatin-mediated apoptosis. J Invest Dermatol 127: 2207-2215, 2007.

26. Flaherty KT: Sorafenib: delivering a targeted drug to the right targets. Expert Rev Anticancer Ther 7: 617-626, 2007.

27. Sharma A, Tran MA, Liang S, et al: Targeting mitogen-activated protein kinase/extracellular signal-regulated kinase kinase in the mutant (V600E) B-Raf signaling cascade effectively inhibits melanoma lung metastases. Cancer Res 66: 8200-8209, 2006.

28. Greenberg AK, Basu S, Hu J, et al: Selective p38 activation in human non-small cell lung cancer. Am J Respir Cell Mol Biol 26: 558-564, 2002

29. Kim MS, Lee EJ, Kim HR and Moon A: p38 kinase is a key signaling molecule for $\mathrm{H}$-Ras-induced cell motility and invasive phenotype in human breast epithelial cells. Cancer Res 63: 5454-5461, 2003. 
30. Sossey-Alaoui K, Ranalli TA, Li X, Bakin AV and Cowell JK: WAVE3 promotes cell motility and invasion through the regulation of MMP-1, MMP-3, and MMP-9 expression. Exp Cell Res 308: 135-145, 2005.

31. Huang X, Chen S, Xu L, et al: Genistein inhibits p38 map kinase activation, matrix metalloproteinase type 2 , and cell invasion in human prostate epithelial cells. Cancer Res 65: 3470-3478, 2005.

32. Zwang $Y$ and Yarden Y: p38 MAP kinase mediates stress-induced internalization of EGFR: implications for cancer chemotherapy. EMBO J 25: 4195-4206, 2006.

33. Lin A: A five-year itch in TNF-alpha cytotoxicity: the time factor determines JNK action. Dev Cell 10: 277-278, 2006.

34. Bowen C, Birrer M and Gelmann EP: Retinoblastoma proteinmediated apoptosis after gamma-irradiation. J Biol Chem 277 44969-44979, 2002.

35. Li T, Dai W and Lu L: Ultraviolet-induced junD activation and apoptosis in myeloblastic leukemia ML-1 cells. J Biol Chem 277: 32668-32676, 2002.

36. Ouwens DM, Gomes de Mesquita DS, Dekker J and Maassen JA Hyperosmotic stress activates the insulin receptor in $\mathrm{CHO}$ cells. Biochim Biophys Acta 1540: 97-106, 2001.

37. Stadheim TA and Kucera GL: c-Jun N-terminal kinase/stress-activated protein kinase (JNK/SAPK) is required for mitoxantrone- and anisomycin-induced apoptosis in HL-60 cells. Leuk Res 26: 55-65, 2002.

38. Liao Y and Hung MC: Regulation of the activity of p38 mitogenactivated protein kinase by Akt in cancer and adenoviral protein E1A-mediated sensitization to apoptosis. Mol Cell Biol 23: 6836-6848, 2003.

39. Garrett JT, Chakrabarty A and Arteaga CL: Will PI3K pathway inhibitors be effective as single agents in patients with cancer? Oncotarget 2: 1314-1321, 2011.

40. Cantley LC: The phosphoinositide 3-kinase pathway. Science 296: 1655-1657, 2002.

41. Blain SW and Massague J: Breast cancer banishes p27 from nucleus. Nat Med 8: 1076-1078, 2002.

42. Inoki $\mathrm{K}, \mathrm{Li} \mathrm{Y}, \mathrm{Zhu} \mathrm{T}, \mathrm{Wu} \mathrm{J}$ and Guan KL: TSC2 is phosphorylated and inhibited by Akt and suppresses mTOR signalling. Nat Cell Biol 4: 648-657, 2002.

43. Nicholson KM and Anderson NG: The protein kinase B/Akt signalling pathway in human malignancy. Cell Signal 14: 381-395, 2002.

44. Testa JR and Bellacosa A: AKT plays a central role in tumorigenesis. Proc Natl Acad Sci USA 98: 10983-10985, 2001.
45. Zhou BP, Liao Y, Xia W, Spohn B, Lee MH and Hung MC: Cytoplasmic localization of $\mathrm{p} 21^{\mathrm{Cip} 1 / \mathrm{WAF} 1}$ by Akt-induced phosphorylation in HER-2/neu-overexpressing cells. Nat Cell Biol 3 245-252, 2001

46. Brugge J, Hung MC and Mills GB: A new mutational AKTivation in the PI3K pathway. Cancer Cell 12: 104-107, 2007.

47. Ma JL, Lee SJ, Duong JK and Stern DF: Activation of the checkpoint kinase Rad53 by the phosphatidyl inositol kinase-like kinase Mec1. J Biol Chem 281: 3954-3963, 2006.

48. Xu J, Gao M, Fan S, et al: Effect of Akt inhibition on scatter factorregulated gene expression in DU-145 human prostate cancer cells Oncogene 26: 2925-2938, 2007.

49. Junttila TT, Akita RW, Parsons K, et al: Ligand-independent HER2/HER3/PI3K complex is disrupted by trastuzumab and is effectively inhibited by the PI3K inhibitor GDC-0941. Cancer Cell 15: 429-440, 2009.

50. Xie L, Chen X and Liu Q: Study of PI3K p110 $\alpha$ expression in cervical lesions. Pract Prev Med 18: 2011.

51. Shankar S and Srivastava RK: Involvement of Bcl-2 family members, phosphatidylinositol 3'-kinase/AKT and mitochondrial p53 in curcumin (diferulolylmethane)-induced apoptosis in prostate cancer. Int J Oncol 30: 905-918, 2007.

52. Barnes NL, Warnberg F, Farnie G, et al: Cyclooxygenase-2 inhibition: effects on tumour growth, cell cycling and lymphangiogenesis in a xenograft model of breast cancer. Br J Cancer 96: 575-582, 2007

53. Marsh Rde W, Rocha Lima CM, Levy DE, Mitchell EP, Rowland KM Jr and Benson AB III: A phase II trial of perifosine in locally advanced, unresectable, or metastatic pancreatic adenocarcinoma. Am J Clin Oncol 30: 26-31, 2007.

54. Cirstea D, Hideshima T, Rodig S, et al: Dual inhibition of akt/ mammalian target of rapamycin pathway by nanoparticle albuminbound-rapamycin and perifosine induces antitumor activity in multiple myeloma. Mol Cancer Ther 9: 963-975, 2010.

55. Floryk D and Thompson TC: Perifosine induces differentiation and cell death in prostate cancer cells. Cancer Lett 266: 216-226, 2008.

56. Zhang M, Fang X, Liu H, Wang S and Yang D: Blockade of AKT activation in prostate cancer cells with a small molecule inhibitor, 9-chloro-2-methylellipticinium acetate (CMEP). Biochem Pharmacol 73: 15-24, 2007. 